\title{
Problematizing the processes of participation in networks: Working through the rhetoric
}

\author{
Dr Jo-Anne Ferreira \\ School of Environment, Griffith University, Nathan, Queensland, Australia \\ Email: j.ferreira@griffith.edu.au
}

Jo-Anne Ferreira convenes the Master of Environment (Education) programme in the Griffith School of Environment, Brisbane, Australia. Her research focuses on the discourses and practices through which the conduct of environmental educators and their students are governed. Her research also extends to the investigation of systemic approaches to change within pre-service teacher education in Australia.

\author{
Associate Professor Julie Davis \\ Queensland University of Technology, Brisbane Australia \\ Email: j.davis@qut.edu.au
}

Julie Davis is a teacher educator and researcher in the School of Early Childhood at Queensland University of Technology, Brisbane, Australia. Her research focuses on early childhood settings as a context for education for sustainability, with a second research interest in systemic approaches to embedding sustainability into teacher education. 
Problematizing the processes of participation in networks: Working through the rhetoric

\title{
(Received XX Month Year; final version received XX Month Year)
}

\begin{abstract}
Participation in networks, both as a concept and process, is widely supported in environmental education as a democratic and equitable pathway to individual and social change for sustainability. However, the processes of participation in networks are rarely problematized. Rather, it is assumed that we inherently know how to participate in networks. This assumption means that participation is seldom questioned. Underlying support for participation in networks is a belief that it allows individuals to connect in new and meaningful ways, that individuals can engage in making decisions and in bringing about change in arenas that affect them, and that they will be engaging in new, non-hierarchical and equitable relationships.
\end{abstract}

In this paper we problematize participation in networks. As an example we use research into a decentralized network - described as such in its own literature - the Queensland Environmentally Sustainable Schools Initiative Alliance in Australia - to argue that while network participants were engaged and committed to participation in this network, 'old' forms of top-down engagement and relationships needed to be unlearnt. This paper thus proposes that for participation in decentralized networks to be meaningful, new learning about how to participate needs to occur.

Keywords: networks, partnerships, educational change, environmental education, sustainability

\section{Introduction}

In light of concerns about the overall effectiveness of environmental education initiatives and the apparent glacial pace of educational change to support social transformation (Priestley, Miller, Barrett and Wallace 2010; Fullan 2005; Cuban 1998), networks are gaining increasing attention for their potential to both embed and scale up change within and across systems. It is believed they offer new ways of building capacity for, and creating the cultural changes required, of large-scale organizations and systems such as schools and schooling and provide insights that will help us deal with our largest societal challenges.

The terms networks and partnerships are often used interchangeably. Partnerships generally refer to more formalized arrangements between individuals and/or organizations, with the goals and outcomes of the partnership often formalized 
through a Memorandum of Understanding (MOU) or other such agreement. In contrast, networks are 'broader than partnerships in that many more institutions are engaged in the working relationship. The network members share a common objective and tend to collaborate on an in-kind basis to derive mutual benefits form (sic) the working relationship' (UNEP n.d. para 6). A network structure is, therefore, a looser set of strategic alliances of collaborators who work together.

Networks as a strategy for change are encouraged by the United Nations Decade of Education for Sustainable Development (UNESCO 2005), in The Gothenburg Recommendations on Education for Sustainable Development (2008), and again in the Bonn Declaration (2009). There is a trend towards the use of networks that support collaborative and equitable relationships as opposed to hierarchical, expert-driven approaches to creating change. While this is the type of network we examine in this paper, our intention is to problematize rather than valorize such networks and these types of relationships. According to Chapman and Aspin (2005 in Black 2008),

[w] ithin education, networks are seen as one of the most promising levers for large-scale reform. This is partly due to the fact that, unlike most of the structures that traditionally drive educational delivery, they have the ability to create a shared purpose and commitment among people and organizations. (7)

\section{Networks}

Networks can be hierarchical and centralized, or flatter in their power structures, when organized as decentralized networks. Networks can be 'formal or informal, fluid or fixed, extensive or intimate, short-term or long-term. They can be expert or representative, centralised or decentralised, open or closed, local or cosmopolitan, geographical or virtual' (Black 2008, 8). Despite this diversity, many networks tend to display common features. These can include: 
- Active involvement of participants;

- Responsiveness to local circumstances;

- The promotion of innovation;

- Agreed and common values and purposes;

- Relationships of trust and respect;

- Equitable/democratic relationships;

- A shared sense of ownership; and

- An effort to bring about change within a whole system.

(Black 2008; Jackson and Burns 2005; Cole 2002)

Within networks, however, there are varied levels of engagement, interaction and control. For example, a centralized network would most likely have a leader or leadership team and a tightly structured agenda and processes for change that have been centrally determined. In contrast, a decentralized network seeks to be more fluid and tries to join "people together in ways that cannot and should not be constrained by formal processes' (Black 2008, 10).

According to complexity theorists Parker and Stacey (1995), when working effectively, non-linear, decentralized networks should enable innovation to flourish because the construction of multiple meaningful relationships creates synergisms, that is, networks of non-linear relationships where the whole is more than the sum of the parts. Such interactions between large numbers of parts in a complex system can create novel forms of interdependent relationships (Stacey 2000) making the most of the creative potential in the many links, connections and relationships that exist between the different parts. Harnessing this potential means that many more possibilities and options for innovation are potentially generated because the network is constantly being energized. In other words, these theorists claim, working in a decentralized networked structure is likely to be 'chaotic', uncertain and cumbersome, but charged with energy, innovation and creativity. Such a structure may also offer 
greater opportunities for 'meaningful' participation, that is, participation that enhances an individual's capacity to effect change.

A decentralized network, it is argued, has the potential to be revolutionary in part because it is difficult to answer the question 'Where is the organization?' Parts of the network can be added to - or taken away - to meet changing needs. The idea is that the network has the social capital to bridge relationships where there are 'structural holes' (Burt 2000). Bridging enables participants to access and share diverse knowledge, resulting in greater creativity and innovation, and thereby improving overall productivity and outcomes. Essential to meaningful participation in a nonlinear network is extensive, non-mediated communications between networked members - where communicative, social processes work to overcome any sense of alienation. According to these chaos and complexity theorists, the adoption of ‘dialogical interaction' (Eijnatten, van Galen and Fitzgerald, 2003) as the primary mode of communication is an essential ingredient for "chaos-informed transformation'(p. 361) and complexity-framed learning. Power sharing is vital, although there may still need to be some level of hierarchy or centralization for the purposes of coordination. In a centralized network, team members generally communicate through one individual to solve problems or to make decisions. In a decentralized network, individuals seek to communicate freely with other partners and process information equally amongst themselves until agreement is reached. As Rosen, Kim and Nam (2010) argue, a group or organization that has a decentralized structure aims to foster 'increased interpersonal homophily and interaction based on the similarity of structural position, and a hierarchical/bureaucratic structure would inhibit interaction and divide members along structural lines' (p.9). We acknowledge, though, that the relationship between the individual and the group in a network is a 
point for problematisation. We share the paradoxical viewpoint of complexity theorist Stacey, that "one forms and is formed by the other at the same time" (2007, p.9). Regardless of this conundrum, research shows that decentralized networks tend to perform better and have more satisfied members than centralized ones. The literature on decentralized networks, however, does not specifically address whether this is because of the individual's sense of participation and sense of embeddedness in the network which, as Passy and Giugni (2007) have found, are key indicators in explaining the different ways in which individuals participate in networks more broadly. Decentralised networks also appear to be more effective than centralized networks in solving complex problems (Rosen 2008).

The question that arises for us from research into complex networks, allied with our practical experience of being part of and investigating such a network, is how well prepared individuals are to be participants within decentralized networks. That is, how easy or challenging is it to be actively involved in such a network, how can participants engage in equitable and democratic relationships, and how can a shared sense of ownership within decentralized networks be built. Our discussion of the notion of participation in decentralized networks in this paper contributes to the problematizing of the concept of participation that is already taking place in environmental education (Reid, Jensen, Nikel and Simovska 2008; Le Grange 2009). Our discussion here is undertaken with reference to one particular network which in its own literature is described as a decentralized network - the Queensland Environmentally Sustainable Schools Initiative (QESSI) Alliance. The QESSI Alliance aims to facilitate the transformation of Queensland State schools into sustainable schools. The Alliance consists of a broad range of organisations with an 
interest in environmental, sustainability and education matters, such as science, geography and environmental education teacher professional associations;

independent and non-State schools associations; non-government organisations both national and state; industries such as waste management; local government councils; government environment, education, natural resources and transport agencies; and environmental education centres.

In our analysis, we utilize complexity theory allied with our own experience, research and reflection. This leads us to argue that we need to learn how to participate in decentralized networks as this is not a clear-cut, straightforward process. Networks, for example, are not power-free zones. Participating in them is complex, and it can be problematic if we bring 'old' ways of thinking - what Bonnett $(2004,129)$ refers to as a 'default disposition' - to participatory processes in decentralized networks. We also point to the need for further debate in the field about whether or not decentralized networks could or should form an 'ideal type' for the field of environmental education. We conclude by arguing that participation is a loaded concept and a practice that warrants more critical reflection by environmental educators.

\section{The QESSI Alliance}

QESSI is the Queensland State Government Department of Education and Training's (DET) implementation of the Australian Federal Government's Australian Sustainable Schools Initiative (AuSSI). AuSSI provides a national framework for the development of sustainable schools in Australia. AuSSI promotes a whole-school approach to education for sustainability that seeks to address issues of social justice and equity in addition to environmental and ecological sustainability. AuSSI parallels similar initiatives such as Sustainable Schools (UK), Enviroschools (New Zealand), Green 
Schools (China and USA), the Environment and Schools Initiative (ENSI) EcoSchools, and the Foundation for Environmental Education's (FEE) Eco-Schools. Importantly, QESSI is configured as a decentralized network (called an Alliance) of people and organizations, both government and non-government, who are all interested in working in and with schools on environmental and sustainability issues.

Extensive meetings and consultations with a wide range of known stakeholders prior to the establishment of QESSI indicated a desire amongst the environmental education community in the region to create a network that supported and advanced the work of individuals and organisations in the region. QESSI was envisaged as a decentralized network partly to overcome the identified barriers and limitations associated with more traditional 'expert' approaches to environmental education that have been accused of downplaying the contextual knowledge of participants (Ferreira, Ryan and Tilbury 2007). The QESSI Alliance, instead, supports a synergistic planning and implementation approach to programs and resources in environmental education in Queensland schools. Thus, the primary focus for QESSI is the development of a decentralized network of individuals and organizations who share ideas, resources and capacities in and for schools (Mackenzie 2005). As a result, the Alliance is an organic body with inclusion of new organisations a matter for discussion and decision at Steering Committee meetings. Criteria for inclusion are that organisations have educational or environmental goals and are working, or wish to work, in and with schools. The intention is that QESSI builds the capacity of existing environmental education program and resource providers to achieve their own organizational goals while, at the same time, contributing more broadly to the collective goal of all schools in Queensland becoming environmentally sustainable schools. A Steering Committee, consisting of representatives from each member 
organization of the QESSI Alliance, works together to set strategic directions and goals for the Alliance and then communicates these to the organisations they represent.

\section{Study context}

The purpose of this section is to provide a brief overview of the study, not to provide a report on the study as a whole but only those parts that are germane to our observations and reflections in this paper. Both authors were members of the QESSI Alliance Steering committee, representing environmental education research organisations. In effect, we were insider researchers, writing about our experiences and observations in these dual roles. We take our lead for undertaking this form of scholarly work from Richardson (2000) who writes eloquently about writing as a "method of inquiry" and from Pelias (2011) who argues that "writing functions as both a realization and a record" (p. 659). Thus, we became involved in a process of "writing into" rather than "writing up" the subject of the QESSI network, "a process of using language to look at, lean into, and lend oneself to an experience" (Pelias, 2011, p.660). Initially, then, we began to note, record and discuss that in many meetings Alliance Steering Committee members were requesting from the government representative that the government take on a more central role in managing and co-ordinating the Alliance activities, rather than being an equal Alliance member. From our understandings of network theory, we noted a disjunction between the equitable and democratic intentions of networks generally, and the reality in this network where members were still seeking to rely on one person and organization as a leader. As educators, we began to think about how people learn to work within networks. This provided the impetus for this study. 
A survey of QESSI Alliance Steering Committee members was undertaken to investigate the perceived weaknesses and strengths of the QESSI Steering Committee as a microcosm of the Alliance. While it may seem strange that our survey was only undertaken with the Steering Committee members, in fact, the Steering Committee, while so named, does not operate as a steering committee; instead it is a body of representatives, one from each organization within the network, a microcosm of the Alliance. The Steering Committee acts as one way through which members are able to share information about their activities and resources, and to identify opportunities for joint projects between network members. This survey was developed based on our own involvement and experiences as members of the QESSI Alliance; through direction-setting and guidelines for the survey by QESSI Alliance Steering Committee members; and after reviewing QESSI documentation. The survey obtained ethical clearance from the researchers' university ethics committee. The ethical clearance granted allows only for the use of de-identified data that precludes the naming the organisations and members of the Alliance and Steering Committee. The survey contained closed questions (using a Likert scale) and open-ended questions (relating to understanding of the Alliance structure; personal and organisational benefits and so on). The survey was in three parts, the first gathering demographic information on participants and the organisation(s) they represented on the Steering Committee. The second part of the questionnaire contained 10 open-ended questions relating to the participation and operation of the QESSI Alliance, such as "How has your involvement in the QESSI Alliance facilitated links, partnerships and synergies with other individuals and organisations?" There were also questions about perceived strengths and weakness in the Alliance approach. The third part of the questionnaire contained 5 closed questions, each with a number of sub-questions (ranging from two 
to eight sub-questions) and Likert scale responses. These questions focussed on understanding perceived levels of and opportunities for involvement in the Alliance. For example, one question asked: "Please indicate the level of opportunity you have had in (a) contributing to the establishment of a framework for working together and (b) for developing the cooperative approach of the network". Not all questions in the survey were germane to our discussion in this paper, hence we do not provide a detailed discussion of all questions, or all findings.

The questionnaire was emailed to all 18 members of the Steering Committee of the QESSI Alliance, not including the two researchers. This was followed up by two reminder emails according to a schedule established by the Steering Committee. We achieved a return rate of 15 from 18 or $83 \%$. Data were collated for each closed question and summarized using the Likert scale. Given the small sample size (15) and small number of closed questions (5), it was not necessary to undertake statistical analysis. Qualitative data responses were collated and reviewed by the researchers. These two sources of data were together analysed through an interpretive descriptive approach using the constant comparative method (Strauss and Corbin 1998) of data analysis. Maykut and Moorhouse (1994) describe interpretive-descriptive research as exploratory and reliant on people's words and meanings. This is an iterative process in which responses were read and re-read to determine recurring themes. The researchers negotiated categories and meanings until agreement was reached.

For this paper, relevant findings were:

(a) There was a clear idea from respondents, noted by 12 of 15 , that the QESSI Alliance is something other than the usual response to implementing new ideas about environmental education and sustainability into a system. This is captured by the 
comment 'it is an Alliance, not another program' (Respondent 2). Indeed, a theme running through the responses is the ability of the Alliance model to bring together like-minded government and non-government organisations to work together in Queensland schools.

(b) Respondents agreed (11 out of 15) that a positive feature of the QESSI Alliance was its flexibility in responding to context and need. One respondent commented, for example, 'the model acknowledges that relationships and involvement can change from time to time. It is designed so members of the Alliance can place themselves where they want or need to be and where they fit in' (Respondent 6). Respondents saw the Alliance functioning as a flexible, decentralized network.

(c) Respondents all agreed (15 out of 15 ) that the Alliance built a sense of community and helped to create new synergies between individuals and organisations. The Alliance was seen as effective at bringing together organizations with a shared sense of purpose, and providing opportunities for information sharing and awareness-raising about environmental education and sustainability issues and other participants' programmes and organizations. Respondent 8 , for example, stated that the Alliance is: 'bringing together people with common goals to share experiences and ideas'. Several respondents noted that the dialogue that they now have with other QESSI partners shapes their thinking about environmental and sustainability issues.

In contrast to these positive responses to the network a number of findings also pointed to our suspicion that there may be a disjunction between the equitable and democratic intentions of networks generally, and the reality in this network that 
network members were still seeking to rely on one person or organization as their leader. For example, there was a clearly stated desire for a more traditional structure to the network (such as memoranda of understanding and sub-committees) (9 out of 15) with respondents arguing that this would give more strength to the positioning of the Alliance within their own organizations and would provide a "binding agreement that each QESSI member is committed to" (Respondent 1). Additionally, some respondents identified that an official stamp of approval from the government partner (DET) for Alliance members organizations and programs (7 out of 15) would provide credibility for their organizations and programs within schools. The final indicator of a possible disjuncture between the theory and reality of networks was noted in most respondents (12 out of 15) calling for more funding to be provided to Alliance member organizations by DET.

Ten respondents provided suggestions about enhancing participation in the Alliance with most of these relating to a strengthening of the role of the key government officer involved in the QESSI Alliance. For example, there were calls to increase the time this officer would devote to managing the Alliance. Indeed, we noted in Steering Committee meetings that when the government officer sought to devolve tasks and responsibilities to Alliance members, the calls for this officer to take more control of the Alliance increased. This is another indicator of the disjunction between the theory of a decentralized network and the reality of how the network was functioning in practice. 


\section{Reflections}

What these findings indicate is that while the idea of participating in a decentralized network was highly valued and strongly supported, in practice participants tended to resort to centralized or hierarchical understandings of networks that are fundamentally at odds with the more egalitarian, democratic principles which in theory underlie decentralized networks. For example, the desire for an MOU and/or a stamp of approval indicates that some Alliance members believe that the Alliance has a distinct leader, and that this leader is the government department. This reflects a disjunction between the idea that decentralized networks are based on equitable relationships and beliefs about who really 'owns' the Alliance. This dichotomy negates the very concept of a decentralized network in which all participate and contribute equally.

The ambivalence between greater structure and hierarchy and more open and equitable relationships is also evident in Respondent 1's comments:

the 'glue' that sticks the QESSI members together is very tenuous. This can be viewed as both a strength, that is, a loose coupling concept for the group, OR as a weakness as there is no binding agreement that each QESSI member is committed to. (Respondent 1)

The suggestion of sub-committees is also indicative of the desire for greater structure within the Alliance. However, while sub-committees might speed up decision-making, they can also result in knowledge and decision-making silos. Knowledge and decision-making often becomes privileged to sub-committee members, and 'chopped up' for others in the network thus limiting meaningful participation in the network and reducing the opportunities for innovation.

Our study thus indicates that while individuals may show a commitment to decentralized networks in theory, when it came to participating in one in practice, many participants in the QESSI Alliance showed a tendency to revert to their 
established ways of knowing and doing, such as looking for someone (in this case the government) to take on an explicit leadership role. While QESSI was devised and profiled as a decentralized network, our study suggests that most participants in the Alliance have been trained for and, to varying degrees, continue to operate within mind-sets and organizations where power relations and communication are mostly hierarchical and/or centralized. Consequently, while there may be a stated commitment to the QESSI Alliance operating as a flatter, highly participatory network, members bring their prior learning and experiences to the Alliance. It is evident from our study and our reflections on this study that participants can hold, paradoxically, hierarchical/centralized ideas and practices while also believing in the benefits of a decentralized network. These, we argue, are contradictory positions and cannot be sustained if a decentralized network such as the QESSI Alliance is to be fully effective. As Herron (1992 cited in Sterling 2003) has argued,

today, a significant minority have abandoned the Newtonian-Cartesian belief system in favour of some elaboration of a systems theory worldview. But it may be that they, and certainly the majority of people, still see the world in Newtonian-Cartesian terms. It is a big shift for concepts to move from being simply beliefs held in the mind to beliefs that inform and transform the very act of perception. (69)

This quote sums up the essential conundrum that we have identified: there is a mismatch between thinking about participation in decentralized networks and its enactment. However, as Stacey (2003), a leading theorist on complexity and chaos in organisations notes, the point is not to try to solve the paradox but to recognise it and live with it. It is the tensions caused by paradoxes that lead to 'creative novelty' (p.15) and new learning. In this case, the paradox we uncovered through our investigation of the QESSI Alliance Steering Committee has led to exposure of practices that may well undercut the effectiveness of the network; and to the exploration of possible new ways to operate. 
As environmental educators, we need therefore think about whether decentralized networks could or should form an ideal type for the field and to challenge our assumptions that participation in decentralized networks is an easy, natural process. To do this, we need a sort of 'un-learning' of current ways of thinking and practising. Environmental educators need to be engaged in providing new learning that enables participants to feel comfortable in decentralized networks so that their value can be maximised. Specifically, we argue that initiators of networks and alliances ought to pay explicit attention to the processes of participation within these structures from their establishment onwards and then openly work at reframing network relationships. In effect, networks and alliances need to become two-fold 'learning organizations' where members are able to successfully conduct their substantive business - in this case, the development of sustainable schools - and where they un-learn hierarchies and learn new - more equitable - ways of participating. In this way, the how of environmental education becomes as important as the what.

\section{Conclusion}

What became apparent from our study is that members of the QESSI Alliance, while they are partial to the concept and appreciate the potential of working in a network or alliance, 'default' to past practices and ways of working. We suspect this may be the case within many other partnerships, networks and alliances. While repeatedly argued for and promoted as a means for effective engagement in processes of change, there does not appear to be much clarity about how to participate and even less about what strategies and structures might be needed in order to 'learn' to participate effectively within a looser structure such as a decentralized network. At this stage we would like to suggest some preliminary processes and technologies that could enhance network members learning about how to participate in networks. We propose two strategies: 
using meetings as learning spaces and improving communication through maximizing the affordances of new technologies.

How networks operate and how as network members we participate, needs to be learnt. Much learning can occur, for example, in network meetings. Meetings provide a unique opportunity to act as learning spaces about networks, their structures, their functions, their operations, and creating shared understandings of how best a particular network and its members might function. However, there is a hidden curriculum that privileges old ways of relating and acting. We propose that this old knowledge and associated practices needs to be made explicit if it is to be overcome. We suggest that each meeting agenda includes an item devoted to such learning. This could be in the form of discussion around key points of network process or issues, and/or in the form of a suite of games and activities such as network and systems mapping. Another strategy that would help to decentralize the network is to have a rotating Chair who has responsibility for creating the agenda and calling and chairing the meeting. In this way, responsibility for the functioning of the network is further shared.

The second strategy we are proposing is to change the model of communication from a centralized to a dispersed one. The benefits of this to a network are that no one person is acting as the conduit for information within the network. There are a number of ways to achieve this, ranging from well-known strategies such as a communication tree, teleconferences/videoconferences and using e-lists, to utilizing social networking technologies such as wikis, blogs, and chat rooms. While recognizing that these are not a panacea to communication issues and have their own limitations, they are beneficial in that they allow for the boundaries of 
time and space to be diminished, for more equitable and open sharing of information and ideas, and for new relationships to emerge.

Finally, what this study revealed to us is that the field of environmental education would benefit from attending to alternative theoretical approaches to those commonly drawn on. In this paper, we have explored complexity theory to help us better understand why there was such a disjuncture, in the case we looked at, between the theory of networks and their enactment. Complexity theory helped us to better understand the linearity and hierarchy that is embedded in so much of our thinking and acting, even when we are trying to act in new ways. This has led us to argue that even when we are trying to act in networked ways, we need to learn how to do this. This means putting in place some explicit processes that help participants, first, become more conscious of their existing ways of thinking and relating and, second, to actively practice dialogic learning and communicating. Although a small study, we believe our findings make a contribution to the problematizing of the concept of participation within environmental education, so increasingly advocated for. In addition, our findings have implications for the much bigger agenda of reshaping education through democracy, power-sharing and participation.

\section{Notes on Contributors}

\section{References}

Black, R. 2008. Beyond the Classroom: Building New School Networks. Camberwell, Vic: ACER Publishing.

Bonnett, M. 2004. Retrieving Nature: Education for a Post-Humanist Age. Malden, MA: Blackwell Publishing.

Burt, R. 2000. The network structure of social capital. In R. Sutton and B. Staw (Eds.) Research in Organisational Behaviour. Greenwich, CT: JAI Press.

Butts, C. 2009. Revisiting the foundations of network analysis. Science. 325. 414-416. 
Centre for Environment and Sustainability. 2009. The Gothenburg Recommendations on Education for Sustainable Development. Gothenburg, Sweden: Chalmers University of Technology and University of Gothenburg.

Cole, P. 2002. A Framework for School Networks. Melbourne, Vic: Department of Education and Training.

Cuban, L. 1998. Constancy and change in schools (1880s to the present), in P.W. Jackson (Ed) Contributing to Educational Change: Perspectives on Policy and Practice. Berkley, McCutchan. 85-105.

Eijnatten, F., van Galen, M. \& Fitzgerald, L. 2003. Learning dialogically: The art of chaos-informed transformation. The Learning Organisation. 10(6), 361-367.

Ferreira, J., Ryan, L. and Tilbury, D. 2007. Mainstreaming education for sustainable development in initial teacher education in Australia: A review of existing professional development models, Journal of Education for Teaching. 33, No. 2: 225-239.

Fullan, M. 2005. Introduction: Scaling up the educational change process. In M. Fullan (Ed) Fundamental Change: International Handbook of Educational Change. Dordrecht, Netherlands: Springer. 1-2.

Jackson, D. and Burns, M. 2005. Two system-wide network reforms in the UK: Learning themes from the Networked Learning Communities and the Leading Edge Partnership Programmes. Paper presented to the International Congress for School Effectiveness and Improvement. ICSEI Conference, Barcelona, 2-5 January.

Le Grange, L. 2009. Participation and participatory action research (PAR) in environmental education processes: For what are people empowered? Australian Journal of Environmental Education. 25, 3-14.

Mackenzie, C. 2005. Queensland Environmentally Sustainable Schools Initiative (QESSI). ozEENews, 92, 5.

Maykut, P. and Moorhouse, R. 1994. Beginning Qualitative Research: A Philosophical and Practical Guide. London: The Falmer Press.

Parker, D. and Stacey, R. 1995. Chaos, Management and Economics: The Implications of Non-Linear Thinking. St. Leonards, NSW: The Centre for Independent Studies.

Passy, F. and Giugni, M. 2001. Social networks and individual perceptions:

Explaining differential participation in social movements. Sociological Forum. 6, No.1: 123-153.

Pelias, R. 2011. Writing into position: Strategies for composition and evaluation. In The Sage Handbook of Qualitative Research. $4^{\text {th }}$ edition. eds. N. Denzin and Y. Lincoln. 659-668. London: Sage.

Priestley, M., Miller, K., Barrett, L. and Wallace, C. 2010. Teacher learning communities and educational change in Scotland: the Highland experience. British Educational Research Journal. First published on 26 February 2010 (iFirst).

Reid, A., Jensen, B., Nikel, J., and Simovska, V. (Eds) 2008. Participation and Learning: Perspectives on Education and the Environment. Health and Sustainability. New York: Springer Verlag.

Richardson, L. 2000. Writing: a method of inquiry. In Handbook of Qualitative Research eds. N. Denzin \& Y. Lincoln. 923-948. London: Sage. 
Rosen, D., Kim, J. and Nam, Y. 2010. Birds of a feather protest together: Theorizing self-organizing political protests with Flock Theory. Systemic Practice and Action Research. Published online 10 February 2010.

Rosen, D. 2008. Cooperation and coordination in decentralized communication networks. Proceedings of the $41^{\text {st }}$ annual Hawaii International Conference on System Science.

Stacey, R. 2000. Strategic Management and Organisational Dynamics: The Challenge of Complexity. $3^{\text {rd }}$ edition. Harlow, UK: Pearson Education.

Stacey, R. 2007. Strategic Management and Organisational Dynamics: The Challenge of Complexity. $5^{\text {th }}$ edition. Harlow, UK.: Prentice Hall.

Sterling, S. 2003. Whole Systems Thinking as a Basis for Paradigm Change in Education: Explorations in the Context of Sustainability. Unpublished $\mathrm{PhD}$ thesis. University of Bath.

Strauss, A. and Corbin, J. 1998. Basics of Qualitative Research: Techniques and Procedures for Developing Grounded Theory. $2^{\text {nd }}$ Edition. Newbury Park, CA: Sage.

UNESCO. 2005. United Nations Decade of Education for Sustainable Development, Executive Board Report by the Director General on the United Nations Decade of Education for Sustainable Development 172 EX/11. Paris: UNESCO.

UNESCO. (2009) The Bonn Declaration. UNESCO World Conference on Education for Sustainable Development. Bonn, Germany. 31 March - 2 April 2009. Retrieved 12 February 2010 from

http://www.esd-world-conference-2009.org/en/whats-new/news-detail/item/bonndeclaration-now-available-in-8-languages.html

UNEP. (n.d.) Partnerships and Networks. Retrieved 12 February 2010 from http://www.unep.org/dewa/partnerships/index.asp. 